\title{
Understanding daily parenting stresses in caring for children with autism spectrum disorders
}

\author{
A P Simelane, MA \\ School of Humanities, Sol Plaatje University, Kimberley, South Africa \\ Corresponding author: A P Simelane (simelane.ayanda1@gmail.com)
}

\begin{abstract}
Background. There is a growing body of knowledge related to stress levels in parents of children diagnosed with developmental challenges. However, limited research has focused on the stress levels among parents raising children with ASD in the South African context.

Objectives. To determine the stress levels experienced by parents raising children with ASD and whether experiences differ between mothers and fathers.

Methods. An independent-sample $t$-test was conducted to understand the differences between mothers' and fathers' stress levels.

Results. The study found that parents raising children with ASD experience significant stress and that mothers experienced higher parental stress levels than fathers.

Conclusion. The results of this study are pertinent to understanding challenges experienced by parents of children with ASD. Genderbased differences in parenting roles are still experienced. Mothers of children with ASD experienced more stress as measured according to the Parenting Daily Hassle Scale. The results suggest that a qualitative follow-up study is required to understand the nature of and background associated with struggles experienced by mothers.
\end{abstract}

S Afr J Child Health 2020;14(3):115-119. https://doi.org/10.7196/SAJCH.2020.v14i3.1596

The study of autism spectrum disorders (ASD) has received significant attention both internationally ${ }^{[1-10]}$ and locally. ${ }^{[7,11-13]}$ ASD is a neurodevelopmental disorder characterised by repetitive behaviours that occur alongside limitations in social communication abilities. ${ }^{[12,14,15]}$ The cause of ASD was not adequately understood when the condition was first identified. Bettelheim ${ }^{[16]}$ suggested a concept of 'refrigerator mothers', which was understood to translate to a 'lack of warmth' or 'lack of love' from the parent, as contributing to ASD in children. ${ }^{[16,17]}$ This notion was propounded in the media, perpetuating the idea that mothers or parents were the main cause of ASD. This idea changed in the wake of further research in the 1960s, with researchers arguing that ASD was in fact a neurodevelopmental disorder. ${ }^{[18]}$

Only limited studies, both locally and internationally, have focused on parents' experiences of caring for children with neurodevelopmental disorders. Although some studies have investigated the effects of caring for a child diagnosed with attentiondeficit/hyperactivity disorders (ADHD) or cerebral palsy on parental experiences, ${ }^{[19-25]}$ studies focusing on the stresses of parents raising children with ASD are virtually absent. ${ }^{[1,26]}$ Of the findings that do appear in literature, most relate to studies that were conducted in North America and Western Europe, and so cannot summarily be applied to the South African (SA) context. ${ }^{[27]}$

International research indicates that the demographic variables of parents raising children with developmental challenges such as ASD may be as a result of their experiences. ${ }^{[28,29]}$ The different parenting roles and the relationship of the specific parent with the child differ depending on the parent's gender and how the parental role is understood. Historically, mothers have assumed the role of caregiver and fathers have been regarded as providers owing to sociocultural mandates. However, these parental roles are changing: family dynamics have changed as women entered the workforce and the role of full-time caregiver is increasingly assumed by 'nannies' or babysitters.
An estimated 1 in 59 children are diagnosed with ASD. ${ }^{[30,31]}$ The global ASD prevalence is estimated to be between $1 \%$ and $2 \%$ of the population. Franz et al. ${ }^{[32]}$ note that population-based prevalence studies are absent in sub-Saharan Africa, but suggest that the SA incidence could be comparable to global statistics. ${ }^{[32]}$ However, little is known about the parental experience of those raising children with ASD in the SA context. Research indicates that parents raising children with neurodevelopmental challenges experience stress and some level of depression, ${ }^{[33]}$ and in this author's opinion such stress will likely also be experienced by parents of children with ASD.

According to the theoretical concept of stress proposed by Folkman and Lazarus, ${ }^{[34]}$ stress is an individual and subjective process that results from an individual's interaction with his or her environment. Folkman and Lazarus ${ }^{[34]}$ postulated that a person deploys coping mechanisms when environmental stress is considered to be overwhelming. From this perspective, parental stress arises when a family is unable to restore adequate functioning mechanisms following the introduction of stress. Several studies indicate that parents raising children with ASD report high levels of chronic stress compared with parents of children exhibiting 'normal' development. ${ }^{[35-39]}$ High levels of stress have been documented among parents of children with ASD in various countries in Europe such as the Anglo-Saxon ${ }^{[36,40]}$ and Spanish-speaking regions, ${ }^{[41]}$ and also in the Chinese-speaking region. ${ }^{[42]}$ However, similar studies have not been conducted in subSaharan Africa, and particularly in SA.

Stress is an important variable in shaping the parental experience associated with raising children with ASD. The current study therefore sought to investigate the stress levels experienced by parents raising children with ASD, with a specific focus on possible differential experiences of mothers and fathers.

\section{Methods}

The study used a quantitative, cross-sectional research design to assess the levels of stress in parents raising children with ASD and 
to examine possible differential experiences between mothers and fathers. Data were collected by means of questionnaires from a sample of parents of children with ASD in three SA cities, namely Johannesburg, Pretoria and Durban.

\section{Participants}

A total of 102 parents of children diagnosed with ASD participated in the study, of which 84 were mothers and 18 were fathers. The mean age (and associated standard deviation) of participants was 39.01 (7.56) years. The demographic distribution of participants was as follows: 81 black, 12 white, 6 Indian and 3 coloured. Participants were purposely recruited from institutions that focus on or are competent in managing children with ASD in the three mentioned cities, namely the Unica School $(n=12)$ in Pretoria, the Key School $(n=7)$ in Johannesburg, Action in Autism $(n=32)$ in Durban, the Johannesburg Hospital School $(n=21)$, the Browns' School $(n=18)$ based in Durban and the Chris Hani Baragwanath Hospital $(n=12)$ in Soweto, Johannesburg. Purposive and snowballing sampling techniques were used owing to the nature of the sample required and taking into account time constraints.

\section{Measures}

Participants completed the Parenting Daily Hassle Scale (PDHS) to determine their levels of stress associated with caring for a child with ASD and a biographical questionnaire, which provided information on the participants' gender, age, race and marital status.

The questionnaire interrogated participants' daily challenges according to five items in each of the four major areas of daily stress in the lives of the parents and carers of young children, namely family, work, caring for young children, and everyday stresses. Parents were asked to rate the hassle they associated with events such as continually cleaning up toys or food, finding suitable babysitters (who are hard to find), getting children ready for outings and leaving on time, or the children demanding to be entertained or played with. The PDHS has two separate Likert scales (frequency and intensity). The two scales are highly correlated $(r=0.78)$ and the internal consistency is considered to be high (Cronbach's $\alpha=0.84$ ). All questionnaires were in English and all participants were conversant in that language.

\section{Data analysis}

Data were analysed using the SPSS software package (version 22) (IBM Corp., USA). As some questions were not answered, a listwise approach was adopted. An independent-samples $t$-test was performed to understand the levels of stress and the differences in mothers' and fathers' experience of daily parental hassles.

\section{Ethical considerations}

Ethical clearance was granted by the Wits Human Research Ethics (Medical) committee (ref. no. M140415), the Gauteng Department of Education and principals of schools outside the government structure (private schools). Prior to the commencement of the study, a research pack was sent to participating parents, which included information sheets, consent forms, all the questionnaires, and proof of ethical clearance from the respective committees.

\section{Results}

Before commencing with data analysis, the researcher considered all the assumptions and considerations of running an independentsamples $t$-test. Homogeneity of variance was confirmed by Levene's test.
The comparison of the two groups' parental daily hassles frequency (PDHF) scores and parental daily hassles intensity (PDHI) scores are presented in Table 1 . PDHF scores were significantly different between the two groups $(t(68)=2.623, p=0.011)$, with mothers experiencing stress more often. Table 1 also shows that the difference in the statistical mean was large (9.107; confidence interval (CI) $2.178-16.035)$ and the effect size $(d)$ was shown to be 0.867 .

The PDHI scores were significantly different $(t(66)=2.952$; $p=0.004$ ), with mothers reporting a higher intensity of stress than fathers. The difference in the statistical mean was large (13.1396; CI 4.25 - 22.027) and the effect size $(d)$ was shown to be 0.908 .

\section{Discussion}

The main objective of the study was to explore the differences in parental stress experienced by mothers and fathers raising children with ASD. Results show that the experiences of the two groups are significantly different. The findings are consistent with those from studies in other countries where parents, and particularly mothers, were found to exhibit elevated parental stress levels, agitation and other physical problems. ${ }^{[43,44]}$ Mothers reported higher scores on both the intensity and frequency scales compared with fathers. These findings may be due to several factors relating to the roles society ascribes to mothers and fathers. Society places different expectations on individuals based on their gender and their value systems and beliefs. These differ from one society to the other. ${ }^{[45]}$ Traditionally, gender roles suggest that women should behave in ways that are feminine, nurturing and family oriented, whereas men should be providers and leaders. ${ }^{[45]}$ However, family dynamics have evolved, and more mothers are now in formal employment. Despite the changing environment, research shows that mothers are still highly active in their traditionally assigned maternal and domestic roles, although some literature does suggest fathers being involved in childcare activities. ${ }^{[46]}$ Regardless of the notable increase in involvement by fathers in their children's lives, mothers still provide in more than half of the care needs and interact more with the child than the working father. ${ }^{[47-50]}$ Pressure stemming from working and caring for children may affect women more than men, and may be exacerbated when caring for a child with a neurodevelopmental condition such as ASD. Tasks associated with caring for a child with ASD exceed the usual type of responsibilities. For example, mothers tend to be the ones who attend to the demands of a child with ASD, rather than fathers. ${ }^{[50]}$

Table 1. Comparison of stress experienced by mothers and fathers in caring for children diagnosed with autism spectrum disorder

\begin{tabular}{|c|c|c|c|c|}
\hline Variable & $t$ & df & $p$-value ${ }^{\star}$ & $\begin{array}{l}\text { Difference in mean } \\
\text { scores }(\mathrm{CI})\end{array}$ \\
\hline \multicolumn{5}{|l|}{ Frequency } \\
\hline $\begin{array}{l}\text { Equal variance } \\
\text { assumed }\end{array}$ & 2.623 & 68 & 0.011 & $\begin{array}{l}9.11 \\
(2.18-16.04)\end{array}$ \\
\hline $\begin{array}{l}\text { Equal variance } \\
\text { not assumed }\end{array}$ & 3.278 & 28.617 & 0.003 & $\begin{array}{l}9.11 \\
(3.42-14.79)\end{array}$ \\
\hline \multicolumn{5}{|l|}{ Intensity } \\
\hline $\begin{array}{l}\text { Equal variance } \\
\text { assumed }\end{array}$ & 2.952 & 66 & 0.004 & $\begin{array}{l}13.14 \\
(4.25-22.03)\end{array}$ \\
\hline $\begin{array}{l}\text { Equal variance } \\
\text { not assumed }\end{array}$ & 3.289 & 26.826 & 0.003 & $\begin{array}{l}13.14 \\
(4.94-21.34)\end{array}$ \\
\hline
\end{tabular}


The findings from the current investigation also support the dominant view that notable parenting challenges are experienced in a household where a father is absent. ${ }^{[51]}$ In such households, the limited role of a father in child care could be detrimental to the growing child, as their position is critical in the child's life and their role is different from that of the mother's.

A body of evidence supports the critical role of a father and the contribution of a father towards the success of the child, ${ }^{[51,52]}$ highlighting the significance of the functions a father typically needs to fulfil in a child's life and without which a child may be affected socially, psychologically and behaviourally. Studies have indicated that when a father is present and engaged in raising a child, their sons present with lower psychological distress and a reduced likelihood of boys engaging in risky behaviours during adolescence has been noted. ${ }^{[33,54]}$ Thus, a father's involvement in a child's upbringing is critical, especially when the child has developmental challenges such as ASD.

\section{Study limitations}

It is important for future researchers to note the limitations in this study. As many participants were not English first-language speakers, the researcher simplified the language of the 'Parenting Daily Hassle' questionnaire used in this study. This may have affected standardisation issues, construct bias, administrative bias or differential item functioning. (The researcher is fluent in several SA languages, which assisted with data interpretation and bridging the language gap.) The sample included more female than male parents, which may affect the generalisation of the findings. The study also focused only on three major SA cities (Pretoria, Johannesburg and Durban), where specialised schooling and healthcare practitioners specialising in managing ASD are likely more available than in smaller towns and rural areas in SA. 'Conventional' nuclear families, consisting of one mother and one father and their dependent children, formed the basis of this study. LGBTQIA or polygamous families or households were not included.

\section{Conclusion}

This research was quantitative in nature and a qualitative study is recommended as follow-up to interview parents on the topic of parental hassles. Practitioners should take into account parents' emotional wellbeing when managing children diagnosed with ASD. There is a need for more support groups for parents, especially mothers, raising and caring for children with ASD to reduce the burden experienced by parents of children with ASD, and it is suggested that parents have access to therapy once their child is diagnosed with ASD. The author also recommends that more attention should be given to schools that cater for children with ASD. Increased community awareness initiatives are recommended to educate the public about the condition, its symptoms and treatment.

\section{Declaration. None.}

Acknowledgements. The author thanks Joshua Kumwenda for critical comments during editing and Lebogang Ramalepe for technical and administrative assistance during manuscript development. The author acknowledges the valuable input from the blind review process.

Author contribution. Sole author.

Funding. None.

Conflicts of interest. None.
1. Christensen DL, Van Naarden Braun K, Baio J, et al. Prevalence and characteristics of autism spectrum disorder among children aged 8 years - autism and developmental disabilities monitoring network, 11 sites, United States, 2012. MMWR Surveill Summ 2018;65(13):1-23. https://doi. org/10.15585/mmwr.ss6513al

2. Goldstein S, Ozonoff S, eds. Assessment of autism spectrum disorder. New York: Guilford Publications, 2018.

3. Klinger LG, Dawson G, Burner K, Crisler M. Autism spectrum disorder. In: Mash EJ, Barkley RA, eds. Child Psychopathology. 3rd ed. New York: Guilford Press, 2014:531-572.

4. McKinnon CJ, Eggebrecht AT, Todorov A, et al. Restricted and repetitive behavior and brain functional connectivity in infants at risk for developing autism spectrum disorder. Biol Psychiatry Cogn Neurosci Neuroimaging 2019;4(1):50-61. https://doi.org/10.1016/j.bpsc.2018.09.008

5. Rescorla LA, Winder-Patel BM, Paterson SJ, et al. Autism spectrum disorder screening with the CBCL/1 $1 / 2-5$ : Findings for young children at high risk for autism spectrum disorder. Autism 2019;23(1):29-38. https://doi. org $/ 10.1177 / 1362361317718482$

6. Naidoo M, Singh S. The oral health status of children with autism spectrum disorder in KwaZulu-Natal, South Africa. BMC Oral Health 2018;18(1):165 https://doi.org/10.1186/s12903-018-0632-1

7. Ramseur K II, De Vries PJ, Guler J, Shabalala N, Seris N, Franz L. Caregiver descriptions of joint activity routines with young children with autism spectrum disorder in South Africa. Pediatr Med 2019;2:6. https://doi.org/10.21037/ pm.2019.03.04

8. Schlebusch L, Dada S, Samuels AE. Family quality of life of South African families raising children with autism spectrum disorder. J Autism Dev Disord 2017;47(7):1966-1977. https://doi.org/10.1007/s10803-017-3102-8

9. Viljoen M, Mahdi S, Griessel D, Bölte S, De Vries PJ. Parent/caregiver perspectives of functioning in autism spectrum disorders: A comparative study in Sweden and South Africa. Autism 2019;23(8):2112-2130. https://doi. org/10.1177/1362361319829868

10. Wetherston V, Gangat S, Shange N, Wheeler K, Sayed Karrim SB, Pahl J. The views and knowledge of parents of children with autism spectrum disorder on a range of treatments. S Afr J Child Health 2017;11(3):117-121. https://doi. org/10.7196/SAJCH.2017.v11i3.1274

11. Bakare MO, Munir KM. Autism spectrum disorders in Africa. In: Mohammadi M-R, ed. A Comprehensive Book on Autism Spectrum Disorders. Rijeka: InTech, 2011:183-194.

12. Abubakar A, Ssewanyana D, Newton CR. A systematic review of research on autism spectrum disorders in sub-Saharan Africa. Behav Neurol 2016;2016:3501910. https://doi.org/10.1155/2016/3501910

13. Schlebusch L, Samuels AE, Dada S. South African families raising children with autism spectrum disorders: Relationship between family routines, cognitive appraisal and family quality of life. J Intellect Disabil Res 2016;60(5):412-423. https://doi.org/10.1111/jir.12292

14. American Psychiatric Association. Diagnostic and statistical manual of mental disorders (DSM-5 $5^{\circ}$. Arlington: American Psychiatric Association, 2013.

15. Lord C, Cook EH, Leventhal BL, Amaral DG. Autism spectrum disorders. Neuron 2000;28(2):355-363.

16. Bettelheim B. The Empty Fortress: Infantile Autism and the Birth of the Self. New York: The Free Press, 1967.

17. Kanner L. Autistic disturbances of affective contact. Nervous Child 1943;2(3):217-250.

18. Pearce J. Dr. Stella Chess, child development specialist, dies at 93. New York Times. 22 March 2007.

19. Ben-Naim S, Gill N, Laslo-Roth R, Einav M. Parental stress and parental self-efficacy as mediators of the association between children's ADHD and marital satisfaction. J Atten Disord 2019;23(5):506-516. https://doi. org/10.1177/1087054718784659

20. Li JJ, Lansford JE. A smartphone-based ecological momentary assessment of parental behavioral consistency: Associations with parental stress and child ADHD symptoms. Dev Psychol 2018;54(6):1086-1098. https://doi. org/10.1037/dev0000516

21. Taylor LA, Climie EA, Yue MW. The role of parental stress and knowledge of condition on incidences of bullying and ostracism among children with ADHD. Child Health Care 2020;49(1):20-39. https://doi.org/10.1080/027396 15.2018.1545580

22. Zaidman-Zait A, Shilo I. Parental ADHD symptoms and inhibitory control in relation to parenting among mothers of children with and without ADHD. J Atten Disorders 2018:1087054718808063.

23. Ballantyne M, Liscumb L, Brandon E, Jaffar J, Macdonald A, Beaune L. Mothers' perceived barriers to and recommendations for health care appointment keeping for children who have cerebral palsy. Glob Qual Nurs Res 2019;6:2333393619868979 https://doi.org/10.1177/2333393619868979

24. Chamudot R, Gross-Tsur V, Horovitz R, Parush S. The Home Program Evaluation Questionnaire - HoPE-Q - for infants with hemiplegic cerebral palsy: Development and psychometric properties. Phys Occup Ther Pediatr 2019;39(3):324-336. https://doi.org/10.1080/01942638.2018.1534920

25. Zuurmond M, O'Banion D, Gladstone M, et al. Evaluating the impact of a community-based parent training programme for children with cerebral palsy in Ghana. PLoS One 2018;13(9):e0202096. https://doi.org/10.1371/journal. pone.0202096 
26. Cridland EK, Jones SC, Caputi P, Magee CA. Being a girl in a boys' world: Investigating the experiences of girls with autism spectrum disorders during adolescence. J Autism Dev Disord 2014;44(6):1261-1274. https://doi. org/10.1007/s10803-013-1985-6

27. Weiss JA, Robinson S, Fung S, Tint A, Chalmers P, Lunsky Y. Family hardiness, social support, and self-efficacy in mothers of individuals with autism spectrum disorders. Res Autism Spect Disord 2013;7(11):1310-1317. https:// doi.org/10.1016/j.rasd.2013.07.016

28. Lopez K, Magaña S, Morales M, Iland E. Parents taking action: Reducing disparities through a culturally informed intervention for Latinx parents of children with autism. J Ethn Cult Divers Soc Work 2019;28(1):31-49. https:// doi.org/10.1080/15313204.2019.1570890

29. Slade N, Eisenhower A, Carter AS, Blacher J. Satisfaction with individualized education programs among parents of young children with ASD. Exceptional Child 2018;84(3):242-260. https://doi.org/10.1177/0014402917742923

30. Developmental Disabilities Monitoring Network Surveillance Year 2010 Principal Investigators, Centers for Disease Control and Prevention. Prevalence of autism spectrum disorder among children aged 8 years -Autism and Developmental Disabilities Monitoring Network, 11 sites, United States, 2010. MMWR Surveill Summ 2014;63(2):1-21.

31. Baio J, Wiggins L, Christensen DL, et al. Prevalence of autism spectrum disorder among children aged 8 years - Autism and Developmental Disabilities Monitoring Network, 11 sites, United States, 2014. MMWR Surveill Summ 2018;67(6):1-23. https://doi.org/10.15585/mmwr.ss6706a1

32. Franz L, Chambers N, Von Isenburg M, De Vries PJ. Autism spectrum disorder in sub-Saharan Africa: A comprehensive scoping review. Autism Res 2017;10(5):723-749. https://doi.org/10.1002/aur.1766

33. Myers SM, Johnson CP, American Academy of Pediatrics Council on Children with Disabilities. Management of children with autism spectrum disorders. Pediatrics 2007;120(5):1162-1182. https://doi.org/10.1542/peds.2007-2362

34. Folkman S, Lazarus RS. If it changes it must be a process: Study of emotion and coping during three stages of a college examination. J Pers Soc Psychol 1985;48(1):150-170. https://doi.org/10.1037//0022-3514.48.1.150

35. Brobst JB, Clopton JR, Hendrick SS. Parenting children with autism spectrum disorders: The couple's relationship. Focus Autism Other Dev Disabl 2009;24(1):38-49. https://doi.org/10.1177/1088357608323699

36. Hoffman CD, Sweeney DP, Hodge D, Lopez-Wagner MC, Looney L. Parenting stress and closeness: Mothers of typically developing children and mothers of children with autism. Focus Autism Other Dev Disabl 2009;24(3):178-187. https://doi.org/10.1177/1088357609338715

37. Lee GK, Lopata C, Volker MA, et al. Health-related quality of life of parents of children with high-functioning autism spectrum disorders. Focus Autism Other Dev Disabl 2009;24(4):227-239. https://doi.org/10.1177/1088357609347371

38. Rao PA, Beidel DC. The impact of children with high-functioning autism on parental stress, sibling adjustment, and family functioning. Behav Modif 2009;33(4):437-451. https://doi.org/10.1177/0145445509336427

39. Wolf L, Goldberg B. Autistic children grow up: An eight to twenty-four year follow-up study. Can J Psychiatry 1986;31(6):550-556. https://doi. org/10.1177/070674378603100613
40. Osborne LA, Reed P. The relationship between parenting stress and behavior problems of children with autistic spectrum disorders. Exceptional Child 2009;76(1):54-73. https://doi.org/10.1177/001440290907600103

41. Cabanillas PP, Sánchez ES, Zaballos LM. Estrés en madres de personas con trastornos del espectro autist. Psicothema 2006;18(3):342-347.

42. Wong C, Odom SL, Hume KA, et al. Evidence-based practices for children, youth, and young adults with autism spectrum disorder: A comprehensive review. J Autism Dev Disord 2015;45(7):1951-1966. https://doi.org/10.1007/ s10803-014-2351-z

43. Habibi Asgar Abad M, Rashidi A, Motevalipour A. Comparing the parenta stress between the mothers of disabled boys and the mothers of normal boys. J Res Behav Sci 2009;2:175-181.

44. Feizi A, Najmi B, Salesi A, Chorami M, Hoveidafar R. Parenting stress among mothers of children with different physical, mental, and psychological problems. J Res Med Sci 2014;19(2):145-152.

45. Blackstone AM. Gender roles and society. J Marriage Fam 2003;57:5-19.

46. Cabrera NJ, Tamis-LeMonda CS, eds. Handbook of Father Involvement: Multidisciplinary perspectives. New York: Routledge, 2013.

47. Darling-Fisher CS, Tiedje LB. The impact of maternal employment characteristics on fathers' participation in child care. Fam Relat 1990;39(1):20 26. https://doi.org/10.2307/584944

48. Wille DE. The 1990s: Gender differences in parenting roles. Sex Roles 1995;33(11-12):803-817.

49. Bates E, O'Connell B, Shore C. Language and communication in infancy. In: Osofsky JD, ed. Handbook of Infant Development. New York: Wiley, 1987.

50. Higgins DJ, Bailey SR, Pearce JC. Factors associated with functioning style and coping strategies of families with a child with an autism spectrum disorder. Autism 2005;9(2):125-137. https://doi.org/10.1177/1362361305051403

51. Freeks F. Responding to the challenge of father absence and fatherlessness in the South African context: A case study involving concerned fathers from the North West Province. Stellenbosch Theol J 2017;3(1):89-113. https://doi. org/10.17570/stj.2017.v3n1.a05

52. Coakley J. The good father: Parental expectations and youth sports. Leisure Stud 2006;25(2):153-163. https://doi.org/10.1080/02614360500467735

53. Ratele K, Shefer T, Clowes L. Talking South African fathers: A critical examination of men's constructions and experiences of fatherhood and fatherlessness. S Afr J Psychol 2012;42(4):553-563. https://doi. org/10.1177/008124631204200409

54. Yoon S, Bellamy JL, Kim W, Yoon D. Father involvement and behavior problems among preadolescents at risk of maltreatment. J Child Fam Stud 2018;27(2):494-504. https://doi.org/10.1007/s10826-017-0890-6

Accepted 28 October 2019 